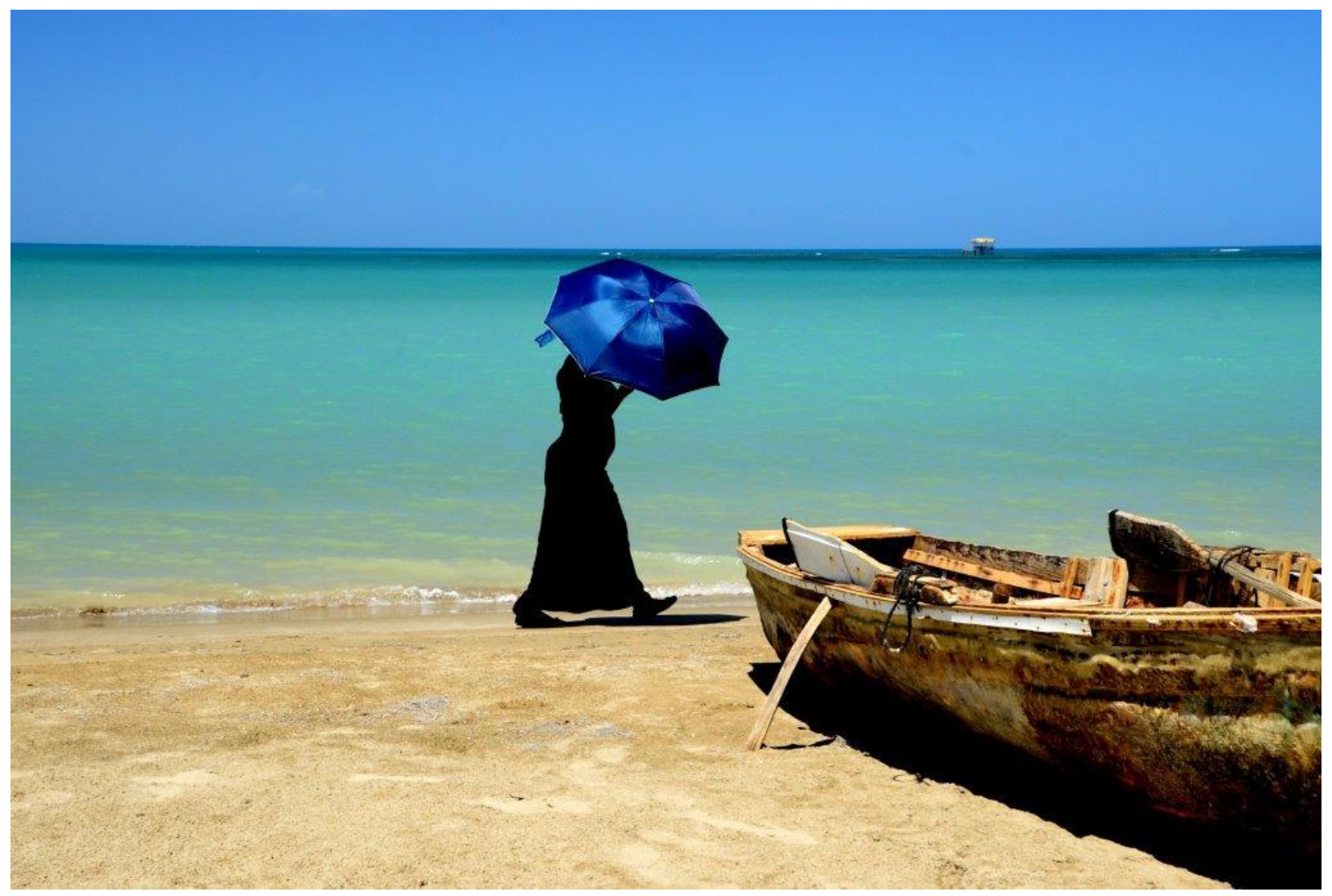

Sabbath by Donnette Zacca

Cultural and Pedagogical Inquiry, Fall 2019, 11(3), pp. 135-136

ISSN 1916-3460 @ 2019 University of Alberta

http://ejournals.library.ualberta.ca/index.php/cpi/index 
Artist: $\quad$ Donette Zacca

Title: "Sabbath"

Date: $\quad 2018$

Medium: Digital Photography

Collection of: The Artist

Photo credit: Donnette Zacca

Provenance: Kingston, Jamaica

\section{Artist Statement}

"Better late than never" is a common refrain in Jamaica. That sentiment is aptly demonstrated in this photograph of an elegantly dressed church goer as she makes her way to church along the beach, reflective and unhurried, amidst the fishing boats.

It was a little warm for our worshipper, but the light, and the colour of the boat were a perfect complement to her elegance.

This photograph was taken at Parottee Bay, St. Elizabeth (on the Southwestern coast of Jamaica). 